\title{
"E o conhecimento da viveza (...) o habilitou para aquele lugar": Duarte Ribeiro de Machado de secretário de embaixada a enviado extraordinário
}

na restauraçáo portuguesa

\author{
Ana Luiza de Castro Pereira*
}

\section{RESUMO}

Neste artigo, analisamos a trajetória de Duarte Ribeiro de Macedo (1610-1680) que, inicialmente, assumiu a função de secretário de embaixada para, posteriormente, chefiar uma missão em Paris como embaixador extraordinário. Os relatos por ele redigidos e emitidos para a Coroa portuguesa revelam um outro lado da vida diplomática daquele período. As dificuldades financeiras enfrentadas por Duarte Ribeiro de Macedo na sua manutenção na corte parisiense foram frequentemente motivos de queixa junto ao rei. Além disso, o embaixador revelou-se como um atento observador do modus vivendi da Corte francesa. Estar numa corte estrangeira exigiu muito dos representantes diplomáticos portugueses que, mesmo na impossibilidade de se manterem no estrangeiro, sempre tiveram a preocupação de representar a Coroa portuguesa de maneira honrada. Percebe-se que a estadia nas cortes europeias demandava não somente conhecimento político, mas também habilidade para circular nas mais diferentes cortes e conviver com hábitos sociais e culturais bastante distintos. Palavras-chave: diplomacia; Restauração; Portugal; embaixador; Duarte Ribeiro de Macedo.

\section{ABSTRACT}

This paper analyzes the trajectory of Duarte Ribeiro de Macedo (1610-1680), who was initially a Secretary of Embassy and then led a mission in Paris as Envoy Extraordinary. The reports drawn up by him and sent to the Portuguese Crown reveal another side of diplomatic life of that period. The financial difficulties faced by Duarte Ribeiro de Macedo to afford his visit to the French court were often grounds for complaints to the king. Moreover, the ambassador turned out to be a keen observer of the modus vivendi of the French court. Being in

Artigo recebido em 23 de julho de 2013 e aceito em 19 de janeiro de 2014.

DOI - http://dx.doi.org/10.1590/2237-101X015028005

* Doutora em história pela Universidade do Minho, Braga, Portugal, investigadora integrada no Centro de História Além-Mar (Cham), Universidade Nova de Lisboa/Universidade dos Açores. Bolsista de pós-doutoramento da Fundação para Ciência e Tecnologia de Portugal. Lisboa, Portugal. E-mail: aluizacastro@ gmail.com. 
"E o conhecimento da viveza (...) o habilitou para aquele lugar": Duarte Ribeiro de Machado de SECRETÁRIO DE EMBAIXADA A ENVIADO EXTRAORDINÁRIO NA RESTAURAÇÃO PORTUGUESA

a foreign court required much from Portuguese diplomatic representatives, who, even in the impossibility of staying abroad, always cared to honorably represent the Portuguese Crown. Missions to European courts required not only political knowledge, but also the ability to move comfortably in different courts, and deal with quite distinct social and cultural habits. Keywords: diplomacy; Restoration; Portugal; ambassador; Duarte Ribeiro de Macedo.

\section{Introdução}

A diplomacia moderna deu os primeiros passos na Itália do século $\mathrm{XV}^{1}$ com o surgimento da figura do ambasciatore como representante direto do rei e das primeiras embaixadas de caráter permanente. Coube à monarquia espanhola o envio do primeiro representante permanente para o exterior, nomeadamente para a Corte inglesa. $\mathrm{O}$ papel desempenhado por um representante diplomático estava ainda a ser definido, o que fez levou à publicação de tratados que regulamentassem, sobretudo, suas funçôes. Dito isso, obras como a de Jean Hotman de Villieres, De la charge et dignité de l'ambassadeur... (1603-1604), e Abraham de Wiquefort, L'ambassadeur et ses fonctions... (1682), foram fundamentais para esboçar o perfil de um ambasciatore. Com a definição do papel que um representante diplomático devia assumir no contexto das relaçóes internacionais, viu-se, no século XVIII, o aparecimento de manuais e tratados como o de François Calliéres, De la maniere de negotier avec les souverains... (1716), que passou a ser o manual mais consultado pelos representantes diplomáticos.

A redação desses e outros tratados aconteceu em meio a um contexto político conturbado na Europa. Assolada pela Guerra dos Trinta Anos que tiveram início em 1618, a paz no continente europeu somente foi alcançada em 1648 com os Tratados de Münster e Osnabrück, também conhecidos como a Paz de Westfália, e que reconheceram, concomitantemente, as Províncias Unidas e a Confederação Suíça. Muitos estudiosos consideram ser a Paz de Westfália o marco inicial da diplomacia moderna por ter sido a primeira vez que a soberania dos Estados envolvidos foi reconhecida. Nesse contexto de acordos de paz, econômicos e geopolíticos, o papel desempenhado pelos representantes diplomáticos ao longo dos séculos assumiu contornos que não ficaram circunscritos somente à representação política do monarca.

\footnotetext{
${ }^{1}$ MATTINGLY, Garret. The first resident embassies: mediaeval Italian origins of modern diplomacy. Speculum, v. 12, p. 423-439, 2003. Disponível em: <www.jstor.org/stable/2849298>. Acesso em: 20 abr. 2011; FUBINI, Riccardo. Aux origines de la balance des pouvoirs: le système politique en Italie au XVe siècle. In: BÉLY, Lucien; RICHEFORT, Isabelle (dirs.). L'Europe des Traités de Westphalie. Esprit de la diplomatie de l'esprit. Paris: PUF, 2000. p. 111-121.
} 
"E o conhecimento da viveza (...) o habilitou para aquele lugar": Duarte Ribeiro de Machado de SECRETÁRIO DE EMBAIXADA A ENVIADO EXTRAORDINÁRIO NA RESTAURAÇÁO PORTUGUESA

Ana Luiza de Castro Pereira

Atualmente, o mundo da diplomacia vem atraindo a atenção de investigadores que buscam compreender a maneira como a função diplomática interferiu na condução de acordos políticos e econômicos entre as naçôes. Contudo, é fundamental perceber as distinçôes existentes relativamente ao caráter ${ }^{2}$ de cada função diplomática, uma vez que sua atribuição estava relacionada, diretamente, com o tipo de enviatura a desempenhar: embaixador ordinário ${ }^{3}$ ou residente; ${ }^{4}$ embaixadores extraordinários; ${ }^{5}$ ministros plenipotenciários. ${ }^{6}$

$\mathrm{Se}$, num primeiro momento, os estudos sobre a diplomacia estiveram focados no papel desempenhado pelos embaixadores no contexto político, nos últimos anos o contexto social e cultural das missões diplomáticas também vem recebendo a atenção dos investigadores. Nesse sentido, as trajetórias de alguns embaixadores portugueses como José da Cunha Brochado, ${ }^{7}$ d. Luís da Cunha ${ }^{8}$ e João Gomes da Silva vêm sendo objeto de estudo

\footnotetext{
${ }^{2}$ António de Moraes Silva em seu Dicionário da língua portuguesa definiu caráter como "o estilo de qualquer pessoa, os atributos, qualidades, propriedades, hábitos, propensôes, costumes, gênio que distinguem e caracterizam o sujeito", mas também a definiçâo da palavra caráter está relacionada ao "Posto, dignidade de alguém”. SILVA, António Moraes. Dicionário da lingua portuguesa. Lisboa: Typographia Lacerdina, 1789. v.
} 1, p. 144.

${ }^{3}$ De acordo com Raphael Bluteau a figura do embaixador ordinário caracterizava-se como aquele que “(...) com a continuação da sua assistência, cultiva a recíproca amizade de um Príncipe com outro, e maneja os negócios que sobrevêm". BLUTEAU, Raphael. Vocabulário português e latino. Coimbra: Collegio das Artes da Companhia de Jesus, Coimbra, 1728, v. 3, p. 41.

${ }^{4}$ A função de residente foi conceituada por Bluteau com “(...) aquele ministro, que faz os negócios de uma República, ou de um Príncipe pequeno, na corte de um Rei”. Ibid., v. 7, p. 282.

${ }^{5}$ A função de embaixador extraordinário, de acordo com Bluteau, era assumida por aquele "(...) que passa para a corte de algum Príncipe, para tratar de algum negócio particular, como a conclusão de um matrimônio, a condução de uma Rainha, congratulaçôes pelo aniversário ou pêsames pelo falecimento de um membro da família real”. Ibid., v. 3, p. 41.

${ }^{6}$ A função de ministro plenipotenciário foi definida por Bluteau como o "Ministro ou Embaixador, que tem do seu Rei, todo o poder necessário para a negociação de uma paz, um casamento”. Ibid., v. 6, p. 548; Antônio de Moraes Silva, em 1789, definiu plenipotenciário como um ministro que tem plenipotência, ou seja, plenos poderes concedidos pelos soberanos, para tratar negócios políticos com outro monarca. Cf. SILVA, António Moraes. Dicionário da língua portuguesa, op. cit. v. 2, p. 459.

${ }^{7}$ José da Cunha Brochado nasceu em 2 de abril de 1651 e faleceu em 27 de setembro de 1733 em Lisboa. Formado em leis pela Universidade de Coimbra, era fidalgo da Casa Real, corregedor do Cível, desembargador do Paço, conselheiro de Estado e da Fazenda, chanceler das Ordens Militares, censor e diretor da Academia Real da História.

${ }^{8}$ D. Luís da Cunha nasceu em 25 de janeiro de 1662 e faleceu em 9 de outubro de 1749 em Paris. Formado em direito canônico, era sócio da Academia Real de História, arcediago da Sé de Évora, corregedor de Tavira, provedor de Coimbra, desembargador do Porto e da Casa da Suplicação e comendador da Ordem de Cristo. Em 1686, aos 24 anos de idade, d. Luís da Cunha foi nomeado desembargador da Relação do Porto assumindo, posteriormente, o cargo de desembargador da Casa de Suplicação. Quase uma década depois foi nomeado, por d. Pedro II, enviado extraordinário em Londres para substituir o visconde da Fonte Arcada. Posteriormente, assumiu como segundo ministro plenipotenciário em Utrecht (1712), embaixador extraordinário em Londres (1715), ministro plenipotenciário em Madri (1719-1720), ministro plenipotenciário em Haia (1728-1736) e embaixador em Paris (1737-1749).

${ }^{9}$ Joáo Gomes da Silva, o conde de Tarouca, nasceu em 21 de junho de 1671 e faleceu em 19 de novembro de 1738 em Viena. Foi capitâo da Guarda Real de d. Pedro II, mordomo-mor da rainha d. Maria Ana de Áustria. Assumiu o cargo de diretor da Academia Real de História. 
"E o conhecimento da viveza (...) o habilitou para aquele lugar": Duarte Ribeiro de Machado de SECRETÁRIO DE EMBAIXADA A ENVIADO EXTRAORDINÁRIO NA RESTAURAÇÃO PORTUGUESA

Ana Luiza de Castro Pereira

na busca por compreender o cenário político em que estavam inseridos e seu papel nesse palco.

Cientes, entretanto, da importância que os embaixadores supracitados tiveram no cenário da política internacional da Idade Moderna, interessa-nos para este artigo trazer para a discussão outro aspecto relacionado com o mundo da diplomacia e que, até então, tem sido pouco estudado: o percurso de um embaixador que primeiramente foi secretário de embaixada e suas observaçóes acerca de uma das cortes por onde andou. Sabe-se que alguns representantes diplomáticos produziram, ao longo da sua "carreira" na diplomacia, uma série de relaçóes em que revelavam pormenores do seu cotidiano nas mais diversas cortes europeias.

Deparamo-nos com a presença de atores cujo percurso de vida merece ser analisado não somente como representantes do rei em momentos políticos, mas também como observadores culturais e promotores da circulação material. O que a consulta da documentação tem revelado é que não foram somente as figuras dos embaixadores, enviados, residentes que despertaram a atenção e a preocupação régia no período em que residiram no estrangeiro. Juntamente com os representantes diplomáticos, um séquito composto por secretário do embaixador, ${ }^{10}$ cozinheiros, copeiros, cocheiro, pagens, maître d'hotel, escudeiros, valets de chambre, era escolhido para acompanhá-lo nas missóes. A esse séquito de acompanhantes vemos muitas vezes denominado na documentação como família ${ }^{11}$ do embaixador. Tal escolha era feita cuidadosamente pelo embaixador, uma vez que também os criados eram considerados a imagem da Coroa no estrangeiro. Em muitos casos constata-se que alguns familiares do embaixador eram nascidos e residentes no local onde o embaixador tinha sido designado, atuando, assim, como um elo entre a embaixada e a sociedade onde seria inserido. A manutenção da sua família no estrangeiro foi responsável por inúmeras e recorrentes queixas dos embaixadores, uma vez que a remuneração dos seus familiares era de sua inteira responsabilidade.

Dentre os criados da embaixada, o secretário de embaixada ${ }^{12}$ era aquele cujo perfil distinguia-se dos demais. É importante considerar que a documentação produzida para e pelas embaixadas passava nas mãos dos secretários das mesmas, razão pela qual a escolha era feita diretamente pelo rei. $\mathrm{Na}$ ausência do embaixador, o secretário da embaixada poderia assumir funçóes interinamente. Já o secretário do embaixador era, geralmente, um indivíduo de

\footnotetext{
${ }^{10}$ Era escolhido e remunerado pelo próprio embaixador.

${ }^{11} \mathrm{O}$ conceito de família aplicado neste caso extrapola os laços consanguíneos. Sobre o conceito de família no Antigo Regime, ver MONTEIRO, Nuno Gonçalo. O crepúsculo dos grandes: a casa e o patrimônio da aristocracia em Portugal, 1750-1832. Lisboa: INCM, 2003. Entendia-se por família todos aqueles que acompanhavam os representantes diplomáticos em suas missóes. Nesse contexto, seu comportamento no estrangeiro também devia ser cauteloso e regrado, pois os membros da família de um representante diplomático simbolizavam também, mesmo que em menor escala, sua monarquia.

${ }^{12}$ É importante diferenciar a função de secretário da Embaixada daquela desempenhada pelo secretário do embaixador. O primeiro era nomeado diretamente pelo rei, sendo suas mesadas também de responsabilidade da Coroa.
} 
"E o conhecimento da viveza (...) o habilitou para aquele lugar": Duarte Ribeiro de Machado de SECRETÁRIO DE EMBAIXADA A ENVIADO EXTRAORDINÁRIO NA RESTAURAÇÃO PORTUGUESA

Ana Luiza de Castro Pereira

confiança do embaixador, sendo sua responsabilidade a manutenção do mesmo. Nas próximas páginas analisaremos um dos secretários de embaixada cuja trajetória pessoal e política fez com que fosse possível ocupar um dos cargos mais importantes na política internacional do Antigo Regime, o de enviado extraordinário.

\section{Portugal, a Restauração e as primeiras embaixadas}

No dia $1^{\circ}$ de dezembro de 1640, o palco europeu das relaçóes internacionais foi modificado com a independência de Portugal e a ascensão de d. João IV, duque de Bragança, ao trono na condiçáo de legítimo rei de Portugal. Naquele dia, no Terreiro do Paço em Lisboa, gritaram: "Valorosos Lusitanos, é chegada a hora de acudirmos pela reputação de Portugal, e de comprar com nosso sangue a liberdade da pátria. O Duque de Bragança é nosso legítimo Rei e Senhor natural. Deve-se-lhe a Coroa de direito". ${ }^{13} \mathrm{O}$ momento histórico da Restauração de Portugal é emblemático para traçar o percurso que a monarquia assumiu no cenário das relaçôes internacionais no Antigo Regime. Há quem interprete aquele momento como o de uma rebeliāo e os seus promotores, nesse contexto, foram intitulados de "rebeldes". Os fidalgos ${ }^{14}$ portugueses do $1^{\circ}$ de dezembro de $1640^{15}$ foram, na verdade, somente quatro, sendo os restantes "conspiradores" membros da nobreza provincial. ${ }^{16}$ Segundo Rafael Valladares, a iniciativa do golpe de 1640 não contou, contudo, com o apoio do então herdeiro direto do trono português, d. João, o duque de Bragança. Tal fato acabou impondo uma necessidade peculiar ao movimento a que o autor chamou de "operação cosmética". Segundo Valladares,

Se D. João tivesse aceite encabeçar o golpe teria sido mais fácil justificá-lo, mas uma vez que não foi isso o que aconteceu, o problema tornou-se insolúvel e foi preciso a intervenção nobiliárquica como uma valente vanguarda do duque, sendo a precaução do Bragança louvada como um exemplo de prudência. Assegurados estes requisitos, o golpe foi batizado com o nome de "Restauração". De um reino, e de uma dinastia. ${ }^{17}$

\footnotetext{
${ }^{13}$ LOBO, Francisco Rodrigues. A Corte na aldeia. Lisboa: Círculo de Leitores, 1981. p. 196.

${ }^{14}$ Sobre o papel dos fidalgos portugueses no projeto de independência de Portugal, ver ÁLVAREZ, Fernando Bouza. Entre dos reinos, una patria rebelde. Fidalgos portugueses en la monarquía hispánica después de 1640. Estudis. Revista de História Moderna, Valência, v. 20, p. 83-103, 1994.

${ }^{15}$ As guerras e sublevaçôes que aconteciam, naquele período, um pouco por toda parte na Europa tiveram, no caso português, um desfecho distinto: culminaram de fato com a substituição da monarquia. Tal acontecimento repetiu-se, apenas, na Inglaterra proporcionando, assim, uma aliança militar e diplomática com a Inglaterra de Carlos II, que esteve no centro do ideário político responsável pela assinatura do Tratado de Paz de 1668. VALLADARES, Rafael. A independência de Portugal: guerra e Restauração (1640-1680). Lisboa: A Esfera dos Livros, 2006.

${ }^{16}$ Ibid., p. 272.

${ }^{17}$ Ibid., p. 275.
} 
"E o conhecimento da viveza (...) o habilitou para aquele lugar": Duarte Ribeiro de Machado de SECRETÁRIO DE EMBAIXADA A ENVIADO EXTRAORDINÁRIO NA RESTAURAÇÃO PORTUGUESA

Ana Luiza de Castro Pereira

Contudo, a ascensão ao trono por si só não garantiria a d. João IV o reconhecimento perante as demais monarquias europeias. O embaixador de Florença em missão em Madri expressou sua estranheza com o ocorrido em Portugal referindo a troca de "(...) um rei legítimo e grande por outro que, ainda que nacional, é pequeno e hipotético". 18

A polarização das opiniōes no que dizia respeito à Restauração Portuguesa ${ }^{19}$ foi vivenciada, especialmente, pelos representantes diplomáticos das primeiras missóes. Se alguns monarcas reconheceram a legitimidade do novo rei português identificando-o como aliado, outros encararam sua ascensão ao trono como um episódio de insurreição e rebeldia ${ }^{20}$ dos portugueses contra a monarquia hispânica. Segundo Pedro Cardim, “(...) os enviados de D. João IV foram frequentemente tratados como 'rebeldes', sentindo grandes dificuldades no que tocava ao reconhecimento do seu estatuto diplomático, pois muitos encaravam esses enviados como representantes de um senhor tido como ilegítimo". ${ }^{21}$

Ciente disso, o recém-coroado rei agiu rapidamente e enviou as primeiras missōes diplomáticas, já no ano de 1641, para as principais cortes europeias na época que faziam frente diretamente ao poder de Felipe IV, nomeadamente: Catalunha (janeiro), Inglaterra, França, Províncias Unidas (fevereiro), Suécia/Dinamarca (março), Roma (abril). O critério de escolha dos embaixadores, nesse primeiro momento, esteve voltado para a confiança que o rei depositava nos enviados, declarando que "(...) devem ser escolhidos para este cargo de Embaixador os homens das famílias mais ilustres do Reino, dos ilustres os mais discretos e cortesãos, destes os mais animosos e liberais, dos animosos os mais bem apessoados, e de todos os mais bem acostumados". 22

Contudo, a questão da ocupação do recém-restaurado trono português enfrentaria um revés com a morte de $\mathrm{d}$. João IV em 1656. O momento era particularmente delicado. De acordo com a linha sucessória, o herdeiro direto do trono era Teodósio de Bragança, que não chegou a subir ao trono, uma vez que faleceu antes mesmo de d. João IV, em 1653 . O

${ }_{18}$ Archivio di Stato, Florença, Mediceo, filza 4965, B. Monanni ao Grão-Duque da Toscana, Madrid, 13.12.1640. Citado por VALLADARES, Rafael. A independência de Portugal, op. cit. p. 277.

${ }^{19}$ Em estudo recentemente traduzido para o português sobre a história da Coroa de Portugal e a monarquia hispânica dos Filipes, o espanhol Rafael Valadares utilizou o termo Independência em substituição ao de Restauração para caracterizar o 1o de dezembro de 1640. Segundo o autor, “(...) uma secessão de um Reino no século XVII não acontecia nem era facilmente aceite”. VALLADARES, Rafael. A independência de Portugal, op. cit.

${ }^{20} \mathrm{O}$ alcance do caso da insurreição de Portugal contra a monarquia espanhola foi tão significativo que Wicquefort (diplomata seiscentista e autor de obras como Mémoires touchant les ambassadeurs et les ministres publics e L'ambassadeur et ses functions) fez referência a isso em seu "manual" de teoria política no capítulo "Si les usurpateurs, et les gouverneurs en chefs peuvant envoyer des ambassadeurs". WICQUEFORT, Abraham de. L'ambassadeur et ses fonctions. A Cologne: A Amsterdã: chez les Janss a Waesberge, 1730.

${ }^{21}$ CARDIM, Pedro. Diplomacia portuguesa no Antigo Regime; perfil sociológico e trajetórias. In: MONTEIRO, Nuno Gonçalo; CARDIM, Pedro; CUNHA, Mafalda Soares (Org.). Óptima Pars: elites ibero-americanas do Antigo Regime. Lisboa: Imprensa de Ciências Sociais, Instituto de Ciências Sociais da Universidade de Lisboa, 2005. p. 58

${ }^{22}$ LOBO, Francisco. A Corte na aldeia, op. cit. p. 120. 
"E o conhecimento da viveza (...) o habilitou para aquele lugar": Duarte Ribeiro de Machado de SECRETÁRIO DE EMBAIXADA A ENVIADO EXTRAORDINÁRIO NA RESTAURAÇÃO PORTUGUESA

Ana Luiza de Castro Pereira

herdeiro seguinte na linha de sucessão era, portanto, Afonso VI. ${ }^{23}$ Este, porém, além de não ter sido previamente preparado para assumir o trono, foi acometido, na infância, por uma doença que afetou fisicamente seu lado direito, comprometendo-o para o resto da vida. Associado a isso, os boatos de que um dos efeitos da enfermidade que tinha atacado Afonso VI foi ter deixado sequelas no campo mental fizeram com que se aventasse a possibilidade de adiamento da cerimônia de coroação, que foi, entretanto, mantida, sendo d. Afonso VI aclamado rei em 15 de novembro de 1656. Na impossibilidade de Afonso VI aceder ao trono em função na menoridade, d. João IV tinha registrado a regência nas mãos de d. Luísa de Gusmão, que permaneceria no trono até que d. Afonso atingisse a maioridade completando vinte anos. Contudo, o reinado da regente d. Luísa sofreria, também, um revés quando Luís de Vasconcelos e Sousa, o terceiro conde de Castelo Melhor, juntamente com o conde de Atouguia, destituíram-na e conferiram o trono a Afonso VI. A notícia do falecimento de d. João IV, assim como o conhecimento da instabilidade que a monarquia portuguesa vivenciava no plano sucessório despertaram, na vizinha Espanha, a esperança de recuperar Portugal.

Esse momento delicado na história da sucessão de d. João IV fez com que a criação de uma rede diplomática portuguesa ${ }^{24}$ se tornasse fundamental para estabelecer alianças que fossem capazes de travar o possível avanço da monarquia espanhola ${ }^{25}$ na tentativa de reaver parte do seu antigo reino. Nesse universo, o conceito de "representação" é fulcral para compreender o papel desempenhado por um chefe de missão diplomática no estrangeiro. No Antigo Regime, e não só, o termo "representação" significava "agir em nome de" ou "no lugar de" alguém, e, no caso da diplomacia, do rei. Como representante da figura régia, aquele que fosse nomeado para a função de embaixador deveria possuir três qualidades: nascimento, estudo e experiência. Para uma enviatura de negociação, por exemplo, eram designados preferencialmente embaixadores licenciados em direito. As funçóes a serem desempenhadas pelos embaixadores nas cortes europeias, de acordo com Wicquefort, ${ }^{26}$ estavam fundamentadas na fidelidade ao monarca, sendo o nascimento e a idade aspectos a serem observados na escolha dos representantes diplomáticos.

\footnotetext{
${ }^{23}$ Sobre o reinado de d. Afonso VI, ver XAVIER, Ângela Barreto; CARDIM, Pedro. D. Afonso VI. Lisboa: Círculo de Leitores, 2006; XAVIER, Ângela Barreto; CARDIM, Pedro; BOUZA, Fernando. Festas que se fizeram pelo casamento do rei d. Afonso VI. Lisboa: Quetzal Editores, 1996.

${ }^{24} \mathrm{E}$ fundamental para um investigador que se debruce no estudo da diplomacia portuguesa pós-Restauração a consulta à obra de SANTARÉM, Visconde de. Quadro elementar das relaçóes políticas e diplomáticas de Portugal com as diversas potências do mundo desde o princípio da monarquia portuguesa até aos nossos dias. Lisboa: Impressão Régia, 1828. Já no século XXI, a obra de Ana Leal de Faria, Arquitetos da paz: a diplomacia portuguesa de 1640 a 1815, busca traçar um perfil da rede diplomática portuguesa, assim como pretende analisar o perfil sociológico dos embaixadores que era definido de acordo com a missáo que iam desempenhar. Cf. FARIA, Ana Maria Leal. Arquitetos da paz: a diplomacia portuguesa de 1640 a 1815 . Lisboa, Tribuna, 2008. ${ }^{25}$ Sobre o cenário anterior à Restauração, ver SCHAUB, Jean-Frédéric. Portugal na monarquia hispânica, 1580-1640, Lisboa: Livros Horizonte, 2001.

${ }^{26}$ A sua obra Mémoires touchant les ambassadeurs et les ministres publics foi escrita enquanto esteve preso por suspeita de espionagem no período da Guerra da Holanda.
} 
"E o conhecimento da viveza (...) o habilitou para aquele lugar": Duarte Ribeiro de Machado de SECRETÁRIO DE EMBAIXADA A ENVIADO EXTRAORDINÁRIO NA RESTAURAÇÃO PORTUGUESA

Ana Luiza de Castro Pereira

Percebemos assim que, se, por um lado, os manuais de civilidade do século XVII ensinavam a teoria, por outro, a designação para uma corte estrangeira significava a possibilidade de aplicação prática destas regras, assim como o aprendizado do modus vivendi particular a cada corte.

\section{O cenário internacional e o papel de Duarte Ribeiro de Macedo}

A Europa desde 1618 vinha sendo devastada por guerras que, de maneira geral, tinham enfraquecido todas as monarquias envolvidas. A busca pela paz era, em meados do século, fundamental. As conversaçôes em torno da paz tiveram início em Westfália, ficando os protestantes em Osnabrück e os católicos em Münster. A insistência de Portugal em enviar um representante diplomático resultou na inclusão de Francisco de Andrade Leitão e Luís Pereira de Castro ao corpo diplomático de Muster e de Rodrigo Botelho de Morais ao de Osnabrück, mesmo sem passaportes. Apesar dos esforços, Portugal não foi incluído no acordo de paz na condição de reino independente. Chegava ao fim o período também conhecido como Guerra dos Trinta Anos, mas sem que Portugal estivesse incluído. A luta portuguesa pelo reconhecimento da sua legitimidade na qualidade de monarquia independente continuaria.

É incontestável o papel desempenhado pelos embaixadores no cenário internacional ao longo da história. Tratados de paz, ${ }^{27}$ acordos geopolíticos e de comércio ${ }^{28}$ foram assinados com base nas suas intervençóes, negociaçôes, ou seja, no exercício da arte da diplomacia. Duarte Ribeiro de Macedo ${ }^{29}$ foi, no período pós-Restauração, um dos principais personagens na busca pela consolidação do papel de Portugal no cenário internacional. Nesse cenário, destaca-se Duarte Ribeiro de Macedo por ter sido enviado para Paris, a principal Corte nos seiscentos, em momentos fulcrais para a afirmação da posição portuguesa no cenário internacional.

A participação de Duarte Ribeiro de Macedo no palco da diplomacia ocorreu em dois momentos importantes da história de Portugal no campo das relaçôes internacionais. A primeira, iniciada em 1659, Macedo figurou como secretário da embaixada de d. João da

\footnotetext{
${ }^{27}$ BRASÃO, Eduardo. O conde de Tarouca em Londres: 1709-1710. Lisboa: Imprensa Nacional, 1936; CORTESÃO, Jaime. Alexandre de Gusmáo e o Tratado de Madri. Rio de Janeiro: Instituto Rio Branco, 1950-1960. ${ }^{28}$ FRIGO, Daniela. Ambasciatori e "jus gentium". L'amministrazione della politica estera nel Piemonte del settecento. Roma: Bulzoni Editore, 1991; BÉLY, Lucien. Les relations internationales en Europe, XVIIeXVIIIe. Paris: PUF, 2001; ANDERSON, Matthew Smith. The rise of modern diplomacy. 1450-1919. Londres: Longman, 1993; CLUNY, Isabel. D. Luis da Cunha e a ideia de diplomacia em Portugal. Lisboa: Livros Horizonte, 1999.

${ }^{29}$ Ao longo da sua "carreira" no mundo da diplomacia, Duarte Ribeiro de Macedo manteve, regularmente, contato com grandes homens da sua época. Entre eles, o padre Antônio Vieira. A correspondência trocada com Vieira, no período em que Ribeiro de Macedo esteve em missão na qualidade de embaixador extraordinário, foi publicada postumamente. VIEIRA, António. Cartas do Padre António Vieira da Companhia de Jesus a Duarte Ribeiro de Macedo. Lisboa: Impressão de Eugénio Augusto, 1827.
} 
"E o conhecimento da viveza (...) o habilitou para aquele lugar": Duarte Ribeiro de Machado de SECRETÁRIO DE EMBAIXADA A ENVIADO EXTRAORDINÁRIO NA RESTAURAÇÃO PORTUGUESA

Ana Luiza de Castro Pereira

Costa, o conde de Soure. O envio de um representante diplomático para a Corte parisiense nessa altura tinha um objetivo bastante definido: tentar garantir a participação de Portugal no congresso de paz que teria lugar nos Pirineus, o que, por sua vez, tinha implicaçóes internacionais marcantes para a recém-restaurada monarquia portuguesa. De acordo com Ana Maria Leal de Faria, o envio do conde de Soure para Paris inseria-se num momento em que “(...) tratava-se de não deixar passar uma oportunidade de assinalar a posição portuguesa face a um congresso de paz" ${ }^{30}$ Esse era o momento em que a Espanha buscava salvaguardar seus planos imperiais e a França buscava afirmar o seu poderio. A escolha do conde de Soure para embaixador extraordinário feita então por d. Luísa de Gusmão inseriu-se num momento decisivo para a legitimaçáo da monarquia portuguesa no cenário internacional. Feliciano Dourado, com o caráter de residente na corte parisiense, em carta endereçada a Pedro Vieira da Silva, secretário de Estado, alegava a urgente necessidade de ser enviado para Paris

(...) um Embaixador que saiba dizer e responder porque Sua Eminência é grande mestre e os mais ministros da mesma escolha; um residente não tem préstimo para dar um aviso e em tão boa hora que saiba fazer uma carta, mas quem vier verá a conta em que cá nos têm. ${ }^{31}$

A participação ativa na Embaixada do conde de Soure na Corte parisiense atribuiu a Ribeiro de Macedo o conhecimento necessário para que, uma vez de volta a Portugal, registrasse suas reflexôes sobre o papel de Portugal no cenário das relaçôes internacionais na obra Juizo histórico, jurídico, político, sobre a paz celebrada entre as Coroas de França \& Castela no ano de 1660, ${ }^{32}$ composta de 27 razóes para que Portugal também fizesse parte daquele tratado. As razões para a inclusão de Portugal no tratado “(...) foram elas tão vivas, tão fortes, e tão eficazes, que rompeu a Corte de Paris em uma demonstração tão nova, como foi a de mandar prender o Impressor, e a um francês que falsamente se creu que tinha sido o autor". O retorno de Paris depois da frustrada tentativa de incluir Portugal no tratado de paz franco-espanhol fez com que esse se tornasse um dos aspectos fundamentais do seu discurso desde que a independência fosse confirmada.

O ano de 1668 iniciou e, com ele, um período em que Portugal vivenciava o pleno reconhecimento no cenário internacional. Era necessária, entretanto, a defesa dos interesses econômicos e coloniais em face do avanço da Inglaterra e da Holanda no panorama marítimo. Foi nesse contexto, poucos anos depois de retornar para Portugal, que Ribeiro de Macedo foi nomeado como enviado extraordinário ${ }^{33}$ para aquela que, na época moderna, era uma das

\footnotetext{
${ }^{30}$ FARIA, Ana Maria Homem Leal. Duarte Ribeiro de Macedo. Um diplomata moderno (1618-1680). Lisboa: Instituto Diplomático; Ministério dos Negócios Estrangeiros, 2005. p. 514.

${ }^{31}$ BNL, Reservados, Fundo Geral, Mss. 201, n. 36, Carta ao Secretário de Estado, Paris, 14 de abril de 1659.

${ }^{32}$ MACEDO, Duarte Ribeiro de. Juizo histórico, jurídico, politico sobre a paz celebrada entre as Coroas de França \& Castela no ano de 1660. Lisboa: Officina de Joam da Costa, 1666.

${ }^{33}$ A nomeação de um representante diplomático para uma enviatura no estrangeiro era sempre acompanhada
} 
"E o conhecimento da viveza (...) o habilitou para aquele lugar": Duarte Ribeiro de Machado de SECRETÁRIO DE EMBAIXADA A ENVIADO EXTRAORDINÁRIO NA RESTAURAÇÃO PORTUGUESA

mais importantes cortes da Europa. Assim, no dia 13 de fevereiro de 1668, com sua Carta Credencial passada pelo rei, Duarte Ribeiro de Macedo partiu para a Corte francesa numa fragata inglesa. Um mês depois, o embaixador chegou a Paris tendo sua audiência com Luís XIV em Saint-Germain-em-Laye decorrido no dia 28 de março do mesmo ano. A permanência na Embaixada em Paris, embora a contragosto de Ribeiro de Macedo, estendeu-se até 1677. A estadia na Corte parisiense permitiu-lhe estreitar os contatos com a monarquia francesa, tendo se tornado um grande admirador de Luís XIV e da sua política de engrandecimento da nação que gostaria de ver implementada em Portugal. ${ }^{34}$

Uma vez em Paris na qualidade de embaixador extraordinário, Duarte Ribeiro de Macedo deu início a uma regular e expedita correspondência com a Corte portuguesa que relatava: nascimentos, casamentos, elementos da política externa francesa, assuntos religiosos entre a França e a Santa Sé, os cerimoniais da Corte e questôes relacionadas com as mesadas enviadas pela Coroa portuguesa para o embaixador e os atrasos das mesmas, o que acarretava muito constrangimento.

\section{"E o conhecimento da viveza (...) o habilitou para aquele lugar"}

Tudo que aqui vejo praticar que me parece útil à nossa terra, e ao serviço de S.A., observo e guardo. ${ }^{35}$

Sabe-se que, ao longo do século XVII (e não só), o mundo da diplomacia foi marcado pela teatralização de todos os momentos públicos relacionados com a entrada e estadia de um representante diplomático. Tal fato proporcionava sua integraçáo num mundo de aparências. Os manuais de civilidade, nesse contexto, ensinavam a maneira de estar nessa sociedade de corte, mas sua aprendizagem efetiva estava relacionada com a frequência na boa sociedade.

Apesar de representar um dos mais emblemáticos embaixadores portugueses que atuaram efetivamente na legitimação da monarquia portuguesa pós-Restauração, a análise que daremos início nas próximas páginas não pretende enfocar a política externa portuguesa durante do século XVII. O objetivo é, de fato, analisar a correspondência produzida por Duarte Ribeiro de Macedo tendo em vista as dificuldades que o mesmo

da produção de um documento intitulado "Instrução". Tal documento definia os objetivos da enviatura e quais seriam as obrigaçóes do enviado. Segundo Pedro Cardim, a Instrução era "(...) um documento que, no fundo, era uma espécie de compromisso de prestação de serviços e que criava, antes de mais, obrigaçóes com caráter jurídico." CARDIM, Pedro. Embaixadores e representantes diplomáticos da coroa portuguesa no século XVII. Cultura, v. 15, p. 47-86, p. 71, 2002.

${ }^{34}$ FARIA, Ana Maria Homem Leal de. Duarte Ribeiro de Macedo: um diplomata moderno (1618-1680). Lisboa: MNE, 2005.

${ }^{35}$ ANTT, MNE, Cx. 560, Doc. 2, Ofício de Paris, 18 de abril de 1672. 
"E o conhecimento da viveza (...) o habilitou para aquele lugar": Duarte Ribeiro de Machado de SECRETÁRIO DE EMBAIXADA A ENVIADO EXTRAORDINÁRIO NA RESTAURAÇÃO PORTUGUESA

Ana Luiza de Castro Pereira

enfrentou para manter a representação da monarquia portuguesa nas relaçóes bilaterais $^{36}$ com a França.

E é no papel de um observador dos costumes que passaremos à análise da correspondência de Duarte Ribeiro de Macedo. Nascido em Lisboa, foi batizado em 10 de fevereiro de 1618 e morreu em Alicante em julho de 1680. Filho de Jerônimo Ribeiro, juiz do Cível de Lisboa, com d. Maria de Lagos, não chegou a se casar, deixando seus bens para seu secretário Manuel da Silva Pereira. A trajetória pessoal e política de Duarte Ribeiro de Macedo começou em 1642, quando se formou em artes na Universidade dos Jesuítas de Évora e, posteriormente, em direito cível na Universidade de Coimbra (1647). A influência do pai levou-o a ser admitido na Leitura de Bacharéis no Desembargo do Paço no ano de 1649.

A nomeação de Duarte Ribeiro de Macedo para secretário da Embaixada de Portugal em Paris aconteceu em 1659 e foi recompensada com a mercê do hábito da Ordem de Cristo e $20 \$ 000$ de pensão. Na altura, d. João da Costa escreveu a Duarte Ribeiro de Macedo dizendo:

Para tempos tấo calamitosos, como só que experimentamos é necessário o alívio de ter muito a miúdo novas dos amigos ausentes (...) Sua Majestade chama a V. M. para secretário da embaixada à França que me tem encarregado: e porque me obrigam a partir com muita brevidade peço a V. M. que venha logo sem dilação alguma, para que tenhamos tempo de acomodar seus despachos de V. M. como convém. ${ }^{37}$

Foi armado cavaleiro no dia 1o de abril de 1659 tendo como padrinhos Manuel de Macedo Pereira e Aleixo de Miranda. A partida da comitiva para a França deu-se no dia 13 de abril, “(...) nós embarcamos em uma nau de força inglesa, que tinha vindo do Brasil na monção última, e saímos em conserva de uma nau de guerra da mesma Nação, cujo Capitão se obrigou a comboiar o Conde até o Porto de Ave de Gracia". ${ }^{38} \mathrm{Na}$ hierarquia presente no mundo da diplomacia daquela época, a funçáo de secretário da embaixada era a mais importante depois do embaixador, sendo, em muitos momentos, considerado como seu conselheiro. No caso de Duarte Ribeiro de Macedo, os episódios frequentes de gota que atacavam o embaixador d. João da Costa fizeram com que seu papel na embaixada portuguesa em França assumisse maior relevância.

Já dissemos anteriormente que Duarte Ribeiro de Macedo fez duas entradas na Corte francesa: a primeira como secretário de embaixada e a segunda como enviado extraordiná-

\footnotetext{
${ }^{36}$ Sobre as relaçóes bilaterais entre Portugal e a França pós-Restauração, ver VELHO, B. T. Moraes Leite. Estudo histórico das relaçóes diplomáticas e políticas entre a França e Portugal. Lisboa: Companhia Nacional, 1895-1996; AMZALAK, Moses Bensabat. As relaçôes diplomáticas entre Portugal e a França no reinado de d. João IV, 1640-1656. Lisboa: s.n., 1943.

${ }^{37}$ MACEDO, Duarte Ribeiro. Obras do doutor Duarte Ribeiro de Macedo cavaleiro da Ordem de Christo... Lisboa: na Off. de Antônio Isidoro da Fonseca, 1743. t. I, p. 4.

${ }^{38}$ Ibid.
} 
"E o conhecimento da viveza (...) o habilitou para aquele lugar": Duarte Ribeiro de Machado de SECRETÁRIO DE EMBAIXADA A ENVIADO EXTRAORDINÁRIO NA RESTAURAÇÃO PORTUGUESA

Ana Luiza de Castro Pereira

rio. Relativamente à sua segunda entrada, esta aconteceu no dia 1o de março de 1668 e foi cercada de "(...) particulares demonstraçôes de obséquio, porque ainda estavam frescas as memórias do tempo de Secretário, e pelo espaço de nove anos sustentou em Paris com decoro, e vigilância os interesses de seu Príncipe". ${ }^{39}$

Enquanto esteve em Paris, Duarte Ribeiro de Macedo fez chegar à Corte lisboeta notícias do cotidiano ${ }^{40} \mathrm{e}$ da sociedade parisiense de finais do século XVII que mereceram toda a atenção do rei. A escolha de um representante diplomático para aquela Corte era feita cuidadosamente pelo rei, uma vez que a estadia em Paris exigia muito de um diplomata (política e economicamente). O cerimonial da Corte de Luís XIV era um dos mais complexos e onerosos da Europa devido às frequentes deslocaçôes a Saint-German, Saint-Cloud e a Versailes. Duarte Ribeiro de Macedo chegou a afirmar que “(...) nem tem V. M. inteira informação do luzimento com que aqui vivo, e do que custa viver em Paris" ${ }^{41}$

Apesar da ajuda de custo com a qual todo representante diplomático era enviado para o estrangeiro, o atraso no pagamento da mesma causava grandes transtornos. $\mathrm{O}$ aluguel da residência do embaixador, a contratação de criados (copeiros, cocheiros, pagens, cozinheiros, mordomos etc.) e os gastos com a indumentária, a aquisição de coches suficientemente adornados para tal funçáo, a ornamentaçáo da residência do embaixador que deveria refletir o luxo e o poder da corte que o enviava, tudo era sinônimo de muitos gastos que, nem sempre, eram suportados pela Coroa. Alguns diplomatas, em atitudes extremas, chegaram a suspender o envio da correspondência obrigatória para o Reino até que as ajudas de custo fossem devidamente pagas.

Muitas vezes as fortunas pessoais ${ }^{42}$ dos embaixadores eram utilizadas para complementar a verba enviada pela Coroa. Mas, os momentos festivos mais onerosos para os representantes diplomáticos eram as festas de batismo, os casamentos e os funerais de membros da família real, cujas preparaçóes eram cercadas de grande pompa. E, dos embaixadores estrangeiros, esperava-se não somente a presença, como cumprimento do protocolo na participação das cerimônias, na decoração das carruagens e no uso de vestimentas condizentes com as circunstâncias. Numa carta enviada a d. Nuno Álvares Pereira de Melo, duque de Cadaval, Ribeiro de Macedo dizia:

\footnotetext{
${ }^{39}$ Ibid.

${ }^{40}$ Sobre a vida cotidiana em Portugal no Antigo Regime, ver MATTOSO, José. História da vida privada em Portugal: a Idade Moderna. Lisboa: Círculo dos Leitores, 2011.

${ }^{41}$ IANTT, MNE, Cx. 560, doc. 3, Oficio de Paris, s.d.

${ }^{42} \mathrm{Na}$ cultura política do século XVII, o desempenho de serviços prestados ao rei estava relacionado diretamente com a expectativa de retribuição. Nesse contexto, não foram somente os embaixadores que usaram seu próprio espólio para sua manutenção nas cortes estrangeiras. Os mais altos servidores do rei, nas mais diversas esferas, utilizaram suas fortunas pessoais imbuídos da ideia de que, posteriormente, seriam recompensados. Sobre a economia de favores no Antigo Regime, ver XAVIER, Angela Barreto; HESPANHA, António Manuel. As redes clientelares. In: MATTOSO, José. História de Portugal. O Antigo Regime, 1620-1807. Lisboa: Editorial Estampa, 1993. v. 4, p. 381-393.
} 
"E o conhecimento da viveza (...) o habilitou para aquele lugar": Duarte Ribeiro de Machado de SECRETÁRIO DE EMBAIXADA A ENVIADO EXTRAORDINÁRIO NA RESTAURAÇÃO PORTUGUESA

Ana Luiza de Castro Pereira

Esta corte é inaturável nos gastos, e basta dizer a V. E. que dia de ano-novo custa por regra infalível vinte dobróes a um enviado (...) No nascimento dos Príncipes é estilo fazerem os ministros festas nas Cortes em que se acham, que vêm a se sair com nova libré, fazer um fogo, e pôr na porta uma fonte de vinho ao povo no dia antes do fogo, e dar um banquete aos amigos. Estas demonstrações são coisas inescusáveis, e com mais forçosa razão em uma Corte onde a Rainha nasceu e onde seus parentes hão de fazer festas públicas. ${ }^{43}$

Se, por um lado, a escolha de Duarte Ribeiro de Macedo para chefiar uma missão diplomática em Paris era vista como reconhecimento dos serviços prestados à Coroa portuguesa, por outro, era sinônimo de grandes preocupaçóes, uma vez que tinha sido designado para uma das mais pomposas cortes europeias. Nesse sentido, a origem pouco abastada de Duarte Ribeiro de Macedo acabou acarretando grandes dificuldades na Corte parisiense, o que, por sua vez, originou inúmeras cartas enviadas ao rei do seu representante diplomático. Ribeiro de Macedo chegou a declarar que "(...) os meus ordenados são os meus alimentos”"44 e numa das cartas enviada ao rei afirmava:

Quanto maior é o tempo das minhas faltas, em que conto dez meses com este que acaba, não sei quando sairemos destas afrontas e quando poderão ver os franceses que não padeço a vergonha de comer fiado? Espero que seja quando os ministros de Sua Alteza acabem de entender que é mais conveniente não ter ministros nas cortes estrangeiras, que tê-los nessa forma. Começar o trabalho de sétimo Inverno em Paris sem ter que fazer as provisóes ordinárias, é coisa que passa a desesperação. ${ }^{45}$

As queixas de Duarte Ribeiro de Macedo, na passagem anterior, traduzem sua insatisfação relativamente aos atrasos que as ajudas de custo reais causavam em seu cotidiano. É interessante observar que a argumentação de Macedo para tentar "pressionar” a Coroa a quitar as mesadas em atraso estava relacionada com a aparência. $\mathrm{O}$ que pensaria o monarca francês, a sua corte e os demais ministros estrangeiros diante de um embaixador que tinha dificuldades em se manter e à sua família? Apesar das dificuldades, Duarte Ribeiro de Macedo foi sempre bastante rigoroso no cumprimento do seu papel nas cerimônias que a Corte francesa promoveu. A vida na Corte francesa era vivenciada não somente em Paris, mas nos arredores, e a presença dos embaixadores era requisitada na maioria delas. Até mesmo nas audiências privadas de embaixadores de outras cortes europeias Duarte Ribeiro de Macedo esteve presente.

\footnotetext{
${ }^{43}$ IANTT, MNE, Cx. 560, doc. 20, Oficio de Paris, s.d.

${ }^{44}$ IANTT, MNE, Cx. 560, doc. 2, Oficio de Paris, 3 de agosto de 1670.

${ }^{45}$ IANTT, MNE, Cx. 560, doc. 2, Oficio de Paris, 3 de agosto de 1670, p. 370-372. 
“E o conhecimento da viveza (...) o habilitou para aquele lugar": Duarte Ribeiro de Machado de SECRETÁRIO DE EMBAIXADA A ENVIADO EXTRAORDINÁRIO NA RESTAURAÇÃO PORTUGUESA

Ana Luiza de Castro Pereira

Dentre as cerimônias celebradas pela Corte francesa, a mais dispendiosa era a do luto. O protocolo determinava a ornamentação dos carros (cobertos de negro), vestimentas adequadas para o embaixador e criados que o acompanhassem e a presença nas audiências, o que significava mais investimento. Sabe-se que a sociedade do Antigo Regime era baseada, em grande medida, nas aparências. Segundo o enviado português, “ (...) aqui se apresenta no Louvre uma comédia de aparências, bailes e músicas muito para ver; tem-se apresentado quatro vezes e se continua até o Entrudo quase todos os dias". ${ }^{46}$ Mais adiante, em 1675, novamente referiu que

(...) na Corte passam as noites com uma comédia que intitulavam Teseu, que representam três vezes na semana toda em música com diferentes máquinas e mudanças de teatro; dura mais de três horas. Eu a fui ver duas vezes, o primeiro convidado, e me persuadi que custaria 200.000 cruzados. ${ }^{47}$

Uma sociedade de luxo, pompa e ostentaçáo, que era vivenciada por todos aqueles que estavam direta ou indiretamente ligados ao viver da Corte. No caso dos embaixadores, à questáo do "aparentar" somava-se a da representaçáo que o mesmo fazia da figura do rei. $\mathrm{E}$, como tal, deveria corresponder às expectativas que a Coroa depositou nele e transmitir para o observador da Corte anfitriá toda segurança possível no que dizia respeito ao poder econômico do seu monarca.

Se, politicamente, o embaixador representava seu rei, socialmente os membros da sua "família" também eram vistos como representantes da sua Coroa. Posto isto, nas cerimônias que aconteciam na Corte francesa não era somente o embaixador que deveria vestir-se de acordo com o protocolo; também os membros da comitiva que o acompanhavam no cortejo: o cocheiro, os lacaios e os criados. Apesar das dificuldades financeiras enfrentadas por Ribeiro de Macedo, ele não deixou de festejar, com fogos de artifício, por exemplo, o nascimento da infanta $\mathrm{d}$. Isabel por acreditar que seria indigno, caso não o fizesse. Apesar da exemplar assiduidade do enviado português nas cerimônias da corte de Luís XIV, foram recorrentes as queixas de Duarte Ribeiro de Macedo lamentando-se não poder “(...) andar com o luzimento dos mais ministros". ${ }^{48}$ Mas não foram somente as queixas que permearam a correspondência emitida por Duarte Ribeiro de Macedo para Portugal. O embaixador recebeu também atribuiçôes como: a contratação de oficiais mecânicos especialistas na fabricação de chapéus enviados para a rainha, a responsabilidade pelo pagamento de dívidas contraídas pela rainha e a aquisição e o envio de obras bibliográficas para a composição da Biblioteca Real.

\footnotetext{
${ }^{46}$ RAU, Virgínia. Cenas da vida parisiense na correspondência de Duarte Ribeiro de Macedo (1668-1676). Bulletin des Études Portugaises, Lisboa, v. 30, p. 95-107, p. 98, 1969.

${ }^{47}$ Ibid., p. 99.

${ }^{48}$ IANTT, MNE, Cx. 560, doc. 4, Oficio de Paris, 3 de agosto de 1670.
} 
"E o conhecimento da viveza (...) o habilitou para aquele lugar": Duarte Ribeiro de Machado de SECRETÁRIO DE EMBAIXADA A ENVIADO EXTRAORDINÁRIO NA RESTAURAÇÃO PORTUGUESA

Representante do rei, mediador político e cultural, observador, muitos foram os papéis que os embaixadores desempenharam em suas missóes. Duarte Ribeiro de Macedo, ao longo dos nove anos em que esteve em Paris, relatou pormenorizadamente o viver daquela Corte. A ornamentação dos coches diplomáticos para as cerimônias de entrada e despedida dos embaixadores estrangeiros, a escolha do vestuário (e o impedimento de repetir um traje numa cerimônia), a distinção entre as cerimônias e a maneira como os representantes diplomáticos deviam se comportar, tudo foi descrito. Ao considerarmos o universo da diplomacia, devemos ter em conta dois princípios fundamentais: o da reciprocidade e o da precedência. Relativamente à reciprocidade, Duarte Ribeiro de Macedo disse, certa vez: “(...) fazer aos ministros alheios o que nas suas Cortes se faz aos próprios". ${ }^{49}$ Em um dos relatos sobre a cerimônia, preparada por Luís XIV, para a entrada de um representante diplomático, Duarte Ribeiro de Macedo salientou que:

Aos Enviados manda El-Rei buscar na primeira audiência em uma carroça sua, pelo primeiro e segundo introdutor; quando entram a lhe falar em todas as audiências, lhe tira o chapéu até abaixo e torna a cobrir; fala El-Rei assentado e o Enviado tem o chapéu na máo. O soldado que está de sentinela lhe toma as armas; não há distinção no tratamento dos Enviados..$^{50}$

No caso da entrada de um enviado Turco, Duarte Ribeiro de Macedo, que, assim como os demais representantes diplomáticos, deveria presenciar a cerimônia, relatou que o enviado

(...) entrou a uma galeria, e fazendo três cortesias ao uso turquesco sem tirar o turbante, a última com maior subenviatura, entregou a carta escrita com pergaminho com títulos e letras de ouro. O Rei o esperou sentado em lugar alto, que se fabricou a este fim, e sem tirar o chapéu recebeu a carta fazendo-lhe só uma inclinação com a cabeça. ${ }^{51}$

Apesar de considerar a relevância que Ribeiro de Macedo exerceu no cenário político internacional da sua época, para este artigo a consulta à correspondência por ele produzida foi analisada numa perspectiva sociocultural. Interessou-nos seu papel no cenário da diplomacia como um observador do modus vivendi da Corte francesa, e também como mediador cultural promovendo a difusão da cultura portuguesa em Paris e vice-versa. Propusemo-nos a analisar uma das facetas da correspondência diplomática enviada por Duarte Ribeiro de Macedo à Coroa portuguesa. Informante incansável do rei, ao longo da sua estadia na Corte parisiense Ribeiro de Macedo produziu sistematicamente um significativo volume documental de cartas para o rei e para os demais representantes diplomáticos nas cortes

\footnotetext{
${ }^{49}$ IANTT, MNE, Cx. 560, doc. 12, Oficio de Paris, 31 de julho de 1673.

${ }^{50}$ IANTT, MNE, Cx. 560, doc. 10, Oficio de Paris, s.d.

${ }^{51}$ RAU, Virgínia. Cenas da vida parisiense na correspondência de Duarte Ribeiro de Macedo (1668-1676), op. cit. p. 97.
} 
"E o conhecimento da viveza (...) o habilitou para aquele lugar": Duarte Ribeiro de Machado de SECRETÁRIO DE EMBAIXADA A ENVIADO EXTRAORDINÁRIO NA RESTAURAÇÃO PORTUGUESA

europeias. O cosmopolitismo das cortes estrangeiras, entre elas a parisiense, era vivenciado pelos embaixadores em todas as ocasióes. Os estranhos costumes russos, a riqueza dos trajes dos embaixadores que se destacavam pelo uso de pedras preciosas de várias cores; a maneira como os capuchos se apresentavam com barbas compridas, batinas justas feitas em tecidos de várias cores; a ornamentação das ruas por onde passavam os coches nos dias de festa; os fogos de artifício que coloriam as noites parisienses, tudo era vivido e transmitido pelos representantes diplomáticos de e para todas as partes do mundo da época moderna. Os embaixadores assumiram, nesse contexto, um papel de promotores da circulaçáo material e sociocultural daquele período.

Estar no estrangeiro e, por sua vez, representar um rei não foi tarefa fácil, como foi possível perceber em algumas passagens da correspondência de Duarte Ribeiro de Macedo. As dificuldades que ele encontrou foram, certamente, vivenciadas por outros representantes diplomáticos, mas não comprometeram o empenho nas missóes de representação da Coroa portuguesa. O bom serviço prestado por Duarte Ribeiro de Macedo na qualidade de secretário de embaixada lhe rendeu a nomeação de embaixador extraordinário e, posteriormente, residente. Apesar da trajetória de Duarte Ribeiro de Macedo, não podemos afirmar que, àquela altura, existisse uma "carreira diplomática" a ser seguida. $O$ fato é que a ocupação da função de secretário de embaixada era muito importante no cenário da diplomacia. Além de ser responsável pela redação e organização de toda a documentação produzida na Embaixada, o secretário de embaixada estava apto, em situaçôes de extrema necessidade, a ocupar a posição do embaixador quando este estava ausente. Depois de ocupar a função de embaixador extraordinário na França, Duarte Ribeiro de Macedo foi nomeado para a Corte de Madri, onde permaneceu por dois anos. Sua trajetória, que começou com a nomeação para secretário de embaixada, terminou em 1680, quando faleceu em Alicante a caminho de Turim, onde viria a residir como embaixador. 